\title{
FORMULATION AND EVALUATION OF METRONIDAZOLE TABLETS USING NATURAL GUM
}

\author{
SUDIPTA DAS*, SOUMITRA DAS \\ Department of Pharmaceutics, Netaji Subhas Chandra Bose Institute of Pharmacy, Chakdaha, Nadia, West Bengal, India. \\ Email: sudiptapharmacy6@gmail.com
}

Received: 3 April 2019, Revised and Accepted: 3 May 2019

ABSTRACT

Objectives: The objective of the present study was to formulate the metronidazole tablets using natural Aloe vera gum as binding agent.

Materials and Methods: To determine the binding properties of the extracted $A$. vera gum were used for the preparation of metronidazole tablets and compared with other binding agents such as acacia and sodium carboxymethyl cellulose (CMC). Physical properties such as hardness, friability, disintegration time, and in vitro dissolution rate are the important parameter which determines for each formulation. Three batches of metronidazole tablets are prepared using acacia (F1), sodium CMC (F2), and A. vera gum (F3) as binding agent.

Results: The granules were evaluated by determining the angle of repose $\left(26.01 \pm 0.110-27.18 \pm 0.166^{\circ}\right)$, bulk density, tapped density, Hausner ratio, and Carr's index. It shows satisfactory results. At time $90 \mathrm{~min}$, the percentage release of drug for F1, F2, and F3 was 44.947\%, 31.467\%, and 53.424\%, respectively. The tablets prepared with $A$. vera gum showed faster release profile than other binders.

Conclusion: From the results, it was shown that tablets prepared with $A$. vera gum have good binding properties and also helped tablets for faster release.

Keywords: Aloe vera, Metronidazole, Binder.

(C) 2019 The Authors. Published by Innovare Academic Sciences Pvt Ltd. This is an open access article under the CC BY license (http://creativecommons. org/licenses/by/4. 0/) DOI: http://dx.doi.org/10.22159/ajpcr.2019.v12i6.33914

\section{INTRODUCTION}

Dosage forms usually consist of several materials, in addition to the drug that they convey to the patient. These materials are generally referred to as tablet excipients. An excipient can be defined as any component, other than the active substances, intentionally added to the formulation of a dosage form for the purpose of long-term stabilization and to increase therapeutic enhancement in the final dosage form, such as drug absorption and reducing viscosity [1]. In tablets, the excipients frequently added include diluents, binding agents, disintegrants, lubricants, and glidants [2].

Binders are pharmaceutical excipients that are commonly used in tablet formulations to mix the powders properly and form proper granules and hence generally improve the flow properties of the granules $[3,4]$. They modify the binding properties of the granules by promoting the formation of strong cohesive bonds between particles [5]. They have been used as solutions and in dry forms depending on other ingredients in the formulation and the method of preparation [6]. Gums are mainly long chain, straight or branched chain polysaccharides that contain hydroxyl groups that bond to water molecules [7]. A number of plant gums/hydrocolloids have been used as binding agents, suspending or emulsifying agents in both solid and liquid dosage forms [8, 9].

These gums are generally non-toxic and widely available hence the continued interest [10]. Aloe gum is the yellow juice exudates produced from most aloe varieties. The bulk of research done on aloe has been on its medicinal properties and it has many of such properties. Its medicinal properties include wound healing, purgative, immunostimulation, anti-inflammatory, and promotion of radiation damage repair [11]. The primary components of aloe are aloin, barbaloin, isobarbaloin, aloe-emodin, and resins. It also contains aloetic acid, galacturonic acid, glucosamine, monosaccharides, and polysaccharides.

There is a prevailing need to develop cheaper and easily accessible tablet excipients, especially in developing countries to reduce the cost of production of tablets. The basis of this research is, therefore, to explore the possibility of using Aloe vera gum as a tablet excipient since it is easily cultivatable and readily available. Therefore, our main objectives of the present study were to formulate the metronidazole tablets using natural $A$. vera gum as binding agent and compare with other binders.

\section{MATERIALS AND METHODS}

\section{Chemicals and reagents}

Metronidazole powder (Yellow Chem Pvt. Ltd.), acacia (Loba Chemie), sodium carboxymethyl cellulose (CMC) (Loba Chemie), magnesium stearate (Loba Chemie), microcrystalline cellulose (Merck Ltd.), lactose (Merck Ltd.), talc (Loba Chemie), HCl (International Chemicals, India), and ethanol (Changshu Hongsheng Fine Chemicals Co. Ltd.) were used.

\section{Preparation of metronidazole tablets}

Three batches of the metronidazole tablets were formulated using three binders, namely acacia, sodium CMC, and A. vera gum. Wet granulation method was used in the formulation of the tablets. Metronidazole powder was triturated together with other ingredients (microcrystalline cellulose and lactose) in geometric order using mortar and pestle. Weighed quantity of each binder was mixed with $8 \mathrm{ml}$ of water to form mucilage and then, used to form a damp mass with the powder mix. The damp mass was passed through $1.7 \mathrm{~mm}$ sieve and dried in a hot oven. The resultant dried granules were passed through $1.0 \mathrm{~mm}$ sieve and then through $0.25 \mathrm{~mm}$ sieve to separate the fine from coarse granules. Magnesium stearate was mixed with the fines and coarse granules then added and all mixed together. The granules mixture was compressed into tablets using a single punch machine [12]

\section{Characterization of granules flow characteristics \\ Bulk density}

The bulk density of a material is the ratio of the mass to the volume (including the interparticulate void volume) of an untapped powder sample. The bulk density is obtained by adding known mass of powder 
to a measuring cylinder. The density is calculated as mass/volume. The bulk density is given in $\mathrm{g} / \mathrm{ml}[13]$

Bulk density $=$ Mass of the powder/Bulk volume

\section{Tapped density}

The tapped density is obtained by mechanically tapping a graduated cylinder containing the sample until little further volume change is observed. The tapped density is obtained by mechanically tapping a graduated cylinder containing the sample until little further volume change is observed. The tapping can be performed using different methods. The tapped density is calculated as mass divided by the final volume of the powder $[13,14]$.

Tapped density $=$ Mass of the powder $/$ Tapped volume

\section{Compressibility index or Carr's index and Hausner ratio}

The compressibility index and Hausner ratio are measured of the products ability to settle and permit an assessment of the relative importance of interparticulate interactions. In a free-flowing powder, these interactions are less significant and the bulk and tapped densities will be closer in value. For poorly flowing materials, there are greater interparticulate interactions and a greater difference between the bulk and tapped densities will be observed. The differences are reflected in the compressibility index and Hausner ratio $[13,14]$.

Compressibility index $=($ Tapped density - Bulk density $) /$ Tapped density $\times 100$

Hausner ratio $=$ Tapped density $/$ bulk density

\section{Angle of repose}

This is the maximum angle possible between the surface of a pile of powder or granules and the horizontal plane [14].

$$
\begin{gathered}
\text { Angle of repose }=\tan \theta=h / r \\
\theta=\tan -1(h / r)
\end{gathered}
$$

Where, $\theta=$ angle of repose, $\mathrm{h}=$ height of the heap, and $\mathrm{r}=$ radius of the heap

\section{Evaluation test of metronidazole tablets}

Hardness test

Hardness of tablets was measured by Monsanto hardness tester [15].

\section{Friability Test}

The friability of the tablets was measured by Roche friabilator [16].

\section{Disintegration time}

The disintegration time is measured by the USP disintegration apparatus [16]

\section{Dissolution studies}

Dissolution rate test was performed with an apparatus meeting the requirement of the United States Pharmacopoeia. The dissolution apparatus (Electrolab) Type II operated at $50 \mathrm{rpm}$ was used. The dissolution medium consisted of $900 \mathrm{ml}$ of freshly prepared $0.1 \mathrm{~N}$ $\mathrm{HCl}$ contained in a $1 \mathrm{l}$ beaker. The temperature was maintained at $37 \pm 0.5^{\circ} \mathrm{C}$. Adequate dilutions of the withdrawn samples were made and the absorbance was measured at $278 \mathrm{~nm}$ using the array spectrophotometer (ELICO) [16].

\section{RESULTS AND DISCUSSION}

Natural binders are considered to be very useful constituents for the development of different tablet preparation as safe with less or no side effect. $A$. vera gum shows good binding properties with comparison to acacia and sodium CMC [17].

The bulk density of all three batches F1, F2, and F3 was $0.3547 \pm$ $0.006 \mathrm{~g} / \mathrm{ml}, 0.3220 \pm 0.004 \mathrm{~g} / \mathrm{ml}$, and $0.3179 \pm 0.003 \mathrm{~g} / \mathrm{ml}$, respectively. The tapped densities were $0.4235 \pm 0.006 \mathrm{~g} / \mathrm{ml}, 0.3765 \pm 0.007 \mathrm{~g} / \mathrm{ml}$, and $0.3843 \pm 0.002 \mathrm{~g} / \mathrm{ml}$, respectively. The Carr's index values were $0.1624 \pm 0.012 \%, 0.1442 \pm 0.022 \%$, and $0.1732 \pm 0.008 \%$, respectively. Hausner ratio values were $1.1944 \pm 0.017,1.1700 \pm 0.030$, and 1.2105 \pm 0.017 , respectively. The angles of repose were $26.01 \pm 0.110,26.36$ \pm 0.678 , and $27.18 \pm 0.166$, respectively. All the results were shown in Table 1. It also showed satisfactory results.

The result of hardness test of three batches F1, F2, and F3 was $3.90 \pm$ $0.82,3.75 \pm 0.63$, and $4.10 \pm 0.58$, respectively. The hardness of tablet prepared was acceptable within $4-7 \mathrm{~kg} / \mathrm{cm}^{2}$. If the concentration of the binder increases, the hardness can also be increase and the type of binder change also leads to an increase in hardness value. This may be occurred due to the more solid bond between particles and the concentration of binder increases the hardness value [18].

The percentage friability of F1, F2, and F3 batches was $0.77 \pm 0.010$, $0.57 \pm 0.003$, and $0.63 \pm 0.001$, respectively. The results of friability of

Table 1: Pre-compression parameter of granules

\begin{tabular}{lllll}
\hline S.No & Properties & $\begin{array}{l}\text { F1 (acacia } \\
\text { as binding } \\
\text { agent) }\end{array}$ & $\begin{array}{l}\text { F2 (sodium } \\
\text { CMC as } \\
\text { binding } \\
\text { agent) }\end{array}$ & $\begin{array}{l}\text { F3 (Aloe vera } \\
\text { as binding } \\
\text { agent) }\end{array}$ \\
\hline 1 & $\begin{array}{l}\text { Bulk } \\
\text { density (g/ml) } \\
\text { Tapped }\end{array}$ & $0.3547 \pm 0.006$ & $0.3220 \pm 0.004$ & $0.3179 \pm 0.003$ \\
2 & $0.4235 \pm 0.006$ & $0.3765 \pm 0.007$ & $0.3843 \pm 0.002$ \\
3 & $\begin{array}{l}\text { density (g/ml) } \\
\text { Carr's }\end{array}$ & $0.1624 \pm 0.012$ & $0.1442 \pm 0.022$ & $0.1732 \pm 0.008$ \\
4 & $\begin{array}{l}\text { index (\%) } \\
\text { Hausner ratio }\end{array}$ & $1.1944 \pm 0.017$ & $1.1700 \pm 0.030$ & $1.2105 \pm 0.017$ \\
5 & $\begin{array}{l}\text { Angle of } \\
\text { repose }\end{array}$ & $26.01 \pm 0.110$ & $26.36 \pm 0.678$ & $27.18 \pm 0.166$ \\
\hline
\end{tabular}

*All values are express as mean $\pm(t \times S E M), n=3$. SEM: Standard error of mean, CMC: Carboxymethylcellulose

Table 2: Post-compression result

\begin{tabular}{lllll}
\hline S.No & Properties & F1 & F2 & F3 \\
\hline 1 & Hardness $\left(\mathrm{kg} / \mathrm{cm}^{2}\right)$ & $3.90 \pm 0.82$ & $3.75 \pm 0.63$ & $4.10 \pm 0.58$ \\
2 & Friability (\%) & $0.77 \pm 0.010$ & $0.57 \pm 0.003$ & $0.63 \pm 0.001$ \\
3 & Disintegration & $22 \pm 0.11$ & $18.37 \pm 0.25$ & $14.23 \pm 0.23$ \\
& time (min) & & & \\
\hline
\end{tabular}

*All values are express as mean $\pm(t \times \mathrm{SEM}), \mathrm{n}=6$. SEM: Standard error of mean

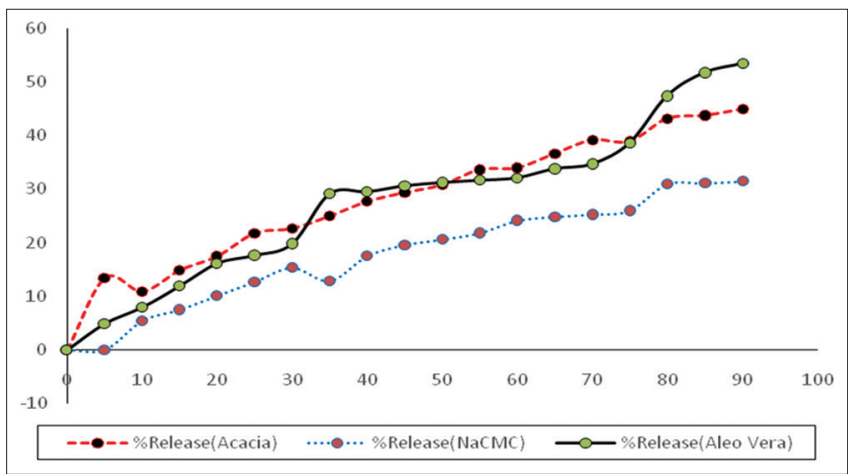

Fig. 1: Percentage release curve of metronidazole tablets using acacia, sodium CMC, and Aloe vera as binding agent 
all batches were within acceptable value. The percentage friability is the reflection of crushing strength [19]. The results are shown in Table 2.

The disintegration times of three batches were $22 \pm 0.11 \mathrm{~min}, 18.37 \pm$ $0.25 \mathrm{~min}$, and $14.23 \pm 0.23 \mathrm{~min}$, respectively. Formation of additional solid bonds that will result in a reduction in the size of the capillary spaces between the particles which reduced the rate of water penetration into the tablets to effect swellability and thus an increase in the disintegration time [20].

In general, the relationship between the binder concentration and percentage of drug release is inverse proportional to each other. If the binder concentration increases, then as a results in the formation of more solid bonds in the tablets which leads to increased tensile strength of the tablets and hence a reduction in disintegration and dissolution rates [21]. The percentage release of drug is shown in Fig. 1 for different binder. At time $90 \mathrm{~min}$, the percentage release of drug for acacia, sodium CMC, and $A$. vera was $44.947 \%$, 31.467\%, and $53.424 \%$, respectively. In graph, it was seen that the percentage release of tablet with binder $A$. vera is increase with time than acacia and sodium CMC. The aloe gum tablet is faster release, whereas the sodium CMC tablet is much slower may be due to its polymeric in nature.

\section{CONCLUSION}

Release study of metronidazole tablets using A. vera gum was better than acacia and sodium CMC. However, long-term stability study is required for future development of these formulations.

\section{ACKNOWLEDGMENT}

The authors would like to thank principal and authority of Netaji Subhas Chandra Bose Institute of Pharmacy, Chakdaha, Nadia, West Bengal, for providing the necessary facilities to perform the present study.

\section{AUTHORS' CONTRIBUTIONS}

Each author is equally contributed.

\section{CONFLICTS OF INTEREST STATEMENT}

There are no conflicts of interest.

\section{REFERENCES}

1. Shilpa PC, Pradeep SP. Pharmaceutical excipients: A review. Int J Adv Pharm Biol Chem 2012;1:21-34.

2. Das AS, Das S, Samanta A. Formulation and evaluation of controlled release floating capsules of ciprofloxacin HCL. Der Pharm Sin 2013;4:72-5
3. Chukwu A. Studies on detarium microcarpium gum II. Investigation as a prolonged release matrix for encapsulated chlorpheniramine maleate. STP Pharma Sci 1994;4:399-403.

4. Disanto AR. Bioavailability and bioequivalency testing in remington. Sci Pract Pharm 1995;19:606.

5. Eichie FE, Amalime AE. Evaluation of the binder effects of the gum mucilages of Cissus populinea sand Acacia senegal on the mechanical properties of paracetamol tablets. Afr J Biotechnol 2007; 19:2208-11

6. Emeje M, Isimi C, Kunle O. Effect of Grewia gum on the mechanical properties of paracetamol tablet formulations. Afr J Pharm Pharmacol 2007;2:1-6.

7. Ibezim EC, Ofoefule SI, Omeje EO, Onyishi VI, Odoh UE. The role of ginger starch as a binder in acetaminophen tablets. Sci Res Essay 2008:3:46-50.

8. Jani JK, Shah DP, Jain VC, Patel MJ, Vithalan DA. Evaluating mucilage from Aloe barbadensis Miller as a pharmaceutical excipient for sustained release matrix tablets. Pharm Technol 2007;31:90-8.

9. Hamman JH. Composition and applications of Aloe vera leaf gel. Molecules 2008;13:1599-616.

10. Kotke MK, Chueh HR, Rodes CT. Comparison of disintegrant and binder activity of three corn starch products. Drug Dev Ind Pharm 1992; 18:2207-23.

11. Prescott JK, Barnum RA. Powder flowability. Pharm Technol 2000;24:60-84

12. Das S, Mandal P. Design, formulation, and evaluation of solid dispersion tablets of poorly water-soluble antidiabetic drug using natural polymer. Asian J Pharm Clin Res 2019;12:195-7.

13. Das S, Roy D. Formulation and evaluation of beta-cyclodextrin complex tablets of ibuprofen. Int J Pharm Res Health Sci 2016;4:1022-4.

14. Nag D, Das S, Samanta A. Formulation and evaluation of immediate release tablet of isoniazid and pyridoxine hydrochloride. World J Parm Pharm Sci 2015;4:1726-40.

15. Haritha B. A review on evaluation of tablets. J Formul Sci Bioavailab 2017;1:2-3.

16. Das S, Samanta A, Dey HS. Formulation, in vitro release kinetics and stability interpretation of sustained release tablets of metformin hydrochloride. Int J Pharm Pharm Sci 2015;7:418-22.

17. Okorie O, Oreh NC. Evaluation of Aloe barbadensis (Aloe Vera) gum as a binder in tablet formulation. Sci Afr 2010;9:119-25.

18. Adolfsson A, Caramella C, Nystrom C. The effect of milling and addition of dry binder on the inter-particulate bonding mechanisms in sodium chloride tablets. Int J Pharm 1998;160:187-95.

19. Ohwoavworhua FO, Ofoefule SI. Evaluation of disintegrant properties of microcrystalline cellulose obtained from Luffa cylindrical in aspirin based formulations. Afr J Pharm 2006;2:54-9.

20. Akin-Ajani OD, Itiola OA, Odeku OA. Effects of plantain and corn starches on the mechanical and disintegration properties of paracetamol tablets. AAPS PharmSciTech 2005;6:E458-63.

21. Odeku OA, Itiola OA. Effects of interacting variables on the tensile strength and the release properties of paracetamol tablets. Trop J Pharm Res 2003;2:147-53. 